\title{
History of Formation of the Russian School of Design
}

\author{
Anna Goncharova \\ Russian State Specialized Arts Academy \\ Moscow, Russia \\ e-mail: goncharovanna@rambler.ru
}

\begin{abstract}
This article is dedicated to the history of design education in Russia from its origin to further development. We discuss the activities of the school of Soviet design VHUTEMAS-VHUTEIN, its new methods of teaching and new design principles, many of which have become canonical for design.
\end{abstract}

Keywords - history of design; the national school of design; artistic and technical education; VHUTEMAS-VHUTEIN

\section{THE EARLY 1900'S}

Since the beginning of the XXth century the artistic education in Russia has had a growing number of serious contradictions caused primarily by the fact that the academic training system was isolating the students from the latest trends in art and did not meet the changing needs that the industrial development was causing in the arts schools.

In 1918 in the post-revolutionary Russia a reform of artistic education was made. Under the resolution of Narkompros the Stroganov School of Industrial Art and the School of Painting, Sculpture and Architecture in Moscow were turned into the First and Second Free Public Arts Workshops respectively (in Russian, SGHMs). The main idea behind the creation of SGHMs was to part from the academic teaching methods and to introduce a new system of individual workshops. Each student was given the right to study in a workshop lead by an artist of his or her choice. Thus, while being part of the First and the Second SGHM in Moscow, many of the most known representatives of the Russian avant-garde (V. Tatlin, K. Malevich, V. Kandinsky, I. Mashkov and others) began to create their own teaching methodologies. Each of them was based on the achievements of modern art and was reviewing the established methods of artists' curriculum.

Such a system of teaching lasted for two years (19181920) and immediately identified a number of contradictions within it. First of all, a complete denial of academic training destroyed everything really valuable that was developed over decades of professional artistic practical training. The students of SGHMs, getting acquainted with the latest artistic trends, instead of getting a broad arts education in fact were perfecting the professional techniques of their SGHM leader. This situation could satisfy neither teacher or student. It has become clear that the rejected academic system of teaching should be replaced with a new, carefully developed educational system.
In 1920, by a decree of Sovnarkom the Higher Arts and Technical Workshops (in Russian, VHUTEMAS) was created through the merger of the First and Second SGHMs. It was aimed to raise "artists-craftsmen of the highest qualification for the industry" and teachers for artistic and technical education. The creation of VHUTEMAS marked the beginning of the second stage of the reform of artistic education in Soviet Russia during which a national school of design was formed. In 1927 VHUTEMAS was renamed in VHUTEIN -Higher Arts and Technical Institute. In 1930 due to the reform of higher education, which was associated with the transfer of many of the technical institutes from the control of Narkompros to industry-specific authorities, VHUTEIN was closed. Instead the following institutes were opened: architectural, arts (now named after Surikov), printing, and the textile industry.

The teachers of VHUTEMAS had to solve some of the greatest challenges: to develop "objective methods" of teaching the artistic disciplines, while contrasting them from the "guild" methods that were used in SGHMs; to develop a common methodology of teaching various artistic disciplines, thereby bringing closer the artistic and technical education within one institute. In addition, based on the specific requirements of the era, it was necessary to refocus the training of artists from easel painting to work in the industry.

\section{THE FACULTIES}

By the end of 1923 VHUTEMAS had developed a twotier system of training. For the first two years students of all disciplines were studying an propaedeutic course on the socalled main faculty, after which they moved over to one of the eight faculties: architecture, painting, sculpture, metallurgy, lumber, ceramic, textile, printing (graphic).

At the main faculty the students got general artistic education. Many valuable methodical finds had been made during the formation of this faculty. This course along with the introductory course "Bauhaus" was a pioneer among all the similar courses of other modern design schools. Propaedeutic course included such disciplines as "Volume", "Space", "Color" and "Graphics" for students of all specialties. Instead of the traditional work with nature it was proposed to create abstract geometric compositions that will identify plastic peculiarities of the elements of the composition in each of the four states of form. For the first two years of studies, all the students of VHUTEMAS were studying the basic types of spatial arts, both with their common, unifying features and special, unique features. The 
students were learning the main elements and means of artistic expression of form: color, space, surface, volume, as well as the methods and language of compositional creativity - proportion, rhythm, dynamics, contrasts, and the patterns of visual perception of the subject environment. The main goal of the propaedeutic course was to develop creative thinking, figurative and spatial imagination, feeling of plastics, and the feeling of line and color. It is here where the universal basics of all artistic specialties were formed.

When talking about design school established in VHUTEMAS-VHUTEIN two faculties are mainly meant metal processing (in Russian, metfak) and wood processing (in Russian, derfak), which were united into one faculty in 1926 (in Russian, dermetfak) with two autonomous branches.

The new method of teaching and the new principles of design were tested for the first time in Russia at the wood and metal processing faculties. They were not based on stylization but on the functional requirements, taking into account the cultural aspect and industrial technology.

\section{DeVEloping TeACHING Methods}

The teachers of the metal and wood processing faculties were A. Rodchenko, El. Lissitzky, V. Tatlin and other representatives of industrial art. The guiding principles of their work were: efficient use of materials and constructions, rational use of space, and the versatility and mobility of products. Any kind of beautification was strongly denied. A lot of attention was paid to the hygienic side of goods. Many of these principles later became canonical for design.

A. Rodchenko was leading the professional development at metal processing faculty for 10 years. The concept of design developed by him can be considered as one of the systems of design education.

Design included several stages: from the formulation of project objectives, analysis of the materials being used, the characteristics of an object's use, its appearance and value to the preparation of work drawings and models of life-size that were made of natural materials.

Learning activities were developed as two separate directions: the construction of an object — "construction", and the metal processing of an object - "composition".

The "Composition" course helped students to master the technology of treating surface, developed skills of artistic and decorative design of an object "based on the consumer needs." The formulation of a particular function subordinated the decoration of an object inferior to the object's function. It could be a trademark, illuminated advertising, drawing for tile, tram stop sign or a badge. Also, decoration of the surface of an object was based not on the manual but on the industrial technology: the ways of stamping were explored, also etching, electroplating, coloring, methods of printing.

The second type of task was designed to train construction skills. Learning activities for construction were made with the increasing complexity from project to project: from the things that perform only one function to multifunctional pieces; from simple to more complex structures; from items made of metal to items combining metal with wood, ceramics, leather and other materials.

The first training assignments in construction were projects to develop the primitive everyday things: a spoon, door handle, pot, iron, scissors, horseshoe. According to Rodchenko, it is necessary to learn to be creative when working with a simple everyday thing, to find an original and rational solution of a design and shape in order to later be able to repeatedly use this solution in the production.

During the study a lot of attention was paid to engineering and technical disciplines which was explained largely by the urgent need to develop Russian industry. It was reflected in the design of multifunctional mobile objects: folding stand-showcase, armchair turning into a bed, transforming tables and so on. The construction of such objects was valued for the ways to use the space, allowing objects to unfold and fold in space. These projects were made by using real materials - this allowed checking a student's ability to work with different materials, as well as his or her knowledge of machines and tools. The artistic side of a project was primarily shown as inventive activity aimed at finding an original, functional and technically justified object.

Students of the wood processing faculty, guided by A. Lavinsky and El. Lissitzky, developed projects of built-in furniture for communal houses, unified and standard furniture, and furniture for specific projects. Lissitzky led the students to design the equipment for real apartments, used both in a mass and experimental construction. Many of his developments marked the beginning of Soviet-style interiors.

When Vladimir Tatlin had come to the wood processing faculty (1928), a new subject emerged — "Culture of materia". Students were making abstract sculpture compositions (installations) made of a combination of glass, wood, wire, etc. The second part of the exercise was the design of objects aimed to match different materials esthetically.

\section{THE EVOLUTION OF LEARNING}

During the same years, the teaching syllabus of metallurgy faculty was changing. New requirements were put in place - the complexity of the design. The senior year students had to develop a complex of objects rather than separate objects, such as equipment for a photo printing shop, museum, bus stop. A new concept appears - "the culture of an object." One of the first tasks for the design - "Selection of ready-made objects": the students designed taking objects from a catalog, i.e. they had to be able to combine objects in a space and choose them based on style, color, and purpose. Rodchenko invented an instrument allowing the exploration of things - the course "Technical Drawing". Drawing becomes one of the stages of design.

After studying the variety of objects the student's next task was to "Simplify the existing object" (to remove any elements of beautification, to identify construction, remove the broken parts); "To improve the existing object" (to make it more comfortable, functional, to find a new color and material); "A new type of an existing object" (to use a new 
production process that would radically change its shape); "New object" (design without a prototype, relying only on functionality, consumer and production factors).

Final assignments for the design included the development of a set of objects and equipment. Project themes varied between "Hostel", "Cinema", "Street", "Library", "Canteen", and "Park". The project has also raised such questions as the creation of an ensemble, search for the achievement of stylistic unity of objects, common color theme, decoration method, etc.

In the end of the 1920s the Soviet school of how to teach designers has developed theoretically, methodologically and organizationally. The faculty of wood and metal processing was improving its ties with the industry. The faculty received requests for specialists from many cities all over the country. A so-called continuous practice of students in the production was introduced: during the whole year, the students alternated work with studies. Graduates of production faculties were getting the title of "engineer-artist" or "process engineer", with the specialization in an industrial field (wood processing or metal processing, textile, ceramic, printing).

Production faculties worked as a foundation of innovative schools in the field of architecture and design. The most influential movements were: in architecture rationalism (N. Ladovsky) and constructivism (A. Vesnin), in design and printing - constructivism (El Lissitzky, A. Rodchenko), school of V. Favorskiy in graphics, ideas of functionalism and standartization (A. Filippov) at the faculty of ceramics.

Summing up the analysis of the activities of the Soviet school of design VHUTEMAS-VHUTEIN, it must be emphasized that it originated as a response to the demand of the time at the moment of big social change, which affected areas of social and cultural relations and materialistic environment of people. All this was a part of special creative and experimental atmosphere in which both teachers and students felt involved in a great cause - they were creating a profession. The leaders of VHUTEMAS viewed the raising of an artist who was also a production worker as a synthetic task of educating a diversified and harmoniously developed employee of a new society. The focus was the identity of the creator, the idea of an universal human being, who has all kinds of project design available to him or her. In general, the school had a humanist view at the social role and practical purpose of the artist in a changing world.

In 1930, with the liquidation of VHUTEIN, the developing school of design has virtually stopped its existence. Later it was necessary to re-create a school of artists-designers and this was done with an active participation of the first graduates of the metal processing faculty Z.N. Bykov and A.A. Galaktionov, who ensured the continuity in the development of design education.

\section{CONCLUSION}

Arts and design education was recreated in 1962 in Moscow with the foundation of the State Scientific and Research Institution of Technical Aesthetics (VNIITE), which was open by the decision of the State Committee of the Board of Ministers of USSR in the area of Science and Technology. The Institution began its activities with the publication of a magazine called "Technical Aesthetics" and with the release of themed issues of the magazine, which were talking in big detail about the first wave of Russian avant-garde that put the Soviet design on one of the first places in the European esthetics of the period. This was the renaissance of the artistic design.

The study of the history and theory of design, creation of methods of design, definition of consumer product requirements, psychophysiology and ergonomics have been the leading trends in the activities of the Institution for nearly 30 years. In fact, VNIITE has become the leading design institution in the USSR and one of the world's centers of design development. Advanced research and development of this institution contributed significantly to the formation of Western European, American and partly Asian design.

Since 1966, the Institution actively searched for an aesthetic and technological model of design education. By the mid- $80 \mathrm{~s}$, as part of the state design development framework, the model of design education offered by VNIITE had become the leading one in the USSR. It was based on continuity and modularity. Developed as part of the concept of continuous design education in the USSR, individual modules and elements of the program helped the further development of education (and not only in design) worldwide.

\section{REFERENCES}

[1] Koveshnikova N.A. The history of design: textbook. M.: Omega-L, 2012. 256 p.: ill.

[2] Koveshnikova N.A. Design: History and Theory: textbook for students of architecture and design profession M.: Omega-L, 2006. 224 p.: ill.

[3] Lavrentiev A.N. The history of design: textbook. M.: Gardariki, 2008. 303 p.: ill.

[4] Mikhailov S., Kuleeva L. Design Basics: textbook for universities. M.: Soyuz Designerov, 2002. 240 p.: ill.

[5] Kholmyanskii L.M., Shchipanov A.S. Design: book for students. M.: Prosveschenie, 1985. 240 p.: ill. 